Research Article

Open Access

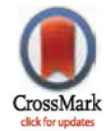

${ }^{1}$ MGGM lab., Agricultural Genetic Engineering ResearchInstitute, Agricultural Research Center, Egypt.

${ }^{2}$ Genetics Department, Faculty of Agriculture, Mansoura University.

${ }^{3}$ Faculty of Pharmacy, October 6 University, Giza, Egypt.

${ }^{4}$ Department of Biodiversity and Crop Improvement, International Center for Agriculture Research in the Dry Areas (ICARDA), Giza, Egypt.

\footnotetext{
* To whom correspondence should be addressed: smahmoud@ageri.sci.eg
}

Citation: Alsamman A.M, Mousa K.H., Nassar A.E., Shereif G.A., Habib P.T. and Ibrahim S.D. (2019). Genome-wide identification and comprehensive study of chickpea anti-fungal genes. Highlights in BioScience, Volume 2. Article ID 20194, dio:10.36462/ H.BioSci.20194

Received: September 15, 2019

Accepted: October 20, 2019

Published: November 10, 2019

Copyright: (C) 2019 Alsamman et al. This is an open access article distributed under the terms of the Creative Commons Attribution License, which permits unrestricted use, distribution, and reproduction in any medium, provided the original author and source are credited.

Data Availability Statement: All relevant data are within the paper and supplementary materials

Funding: The authors have no support or funding to report.

Competing interests: The authors declare that they have no competing interests

\section{Genome-wide identification and comprehensive study of anti-fungal genes in chickpea}

\author{
Alsamman M. Alsamman ${ }^{* 1}$, Khaled H. Mousa ${ }^{2}$, Ahmed E. Nassar ${ }^{2}$, Ghada \\ A. Shereif ${ }^{3}$, Peter T. Habib ${ }^{4}$ and Shafik D. Ibrahim ${ }^{1}$
}

\section{Abstract}

Chickpea is an important crop that delivers nutritious food to the increasing global community and it will become increasingly popular as a result of climate change. Our objective was to use comprehensive data analysis to locate and identify candidate genes for fungal disease resistance. We used a comprehensive bioinformatics pipeline of sequence alignment, phylogenetic analysis, protein chemical and physical properties assessment and domain structure classification. In order to study gene evolution and genetic diversity, we compared these genes with known anti-fungal genes in different species of plants. A total of 19721 protein sequences belonging to 187 plant species have been downloaded from public databases, including the entire chickpea genome. We have successfully identified 23 potential anti-fungal genes in 10 different chromosomes and genomic scaffolds using sequence alignment and gene annotation. $\mathrm{Ca} 2$ and $\mathrm{Ca} 6$ have the highest number of genes followed by $\mathrm{Ca} 3$ and $\mathrm{Ca} 4$. Anti-fungal chickpea proteins have been identified as cysteine-rich (10), thaumatin (6), pathogenesis (4) and plasmodesmata (3) proteins. Analysis of the chemical and physical correlation of anti-fungal proteins revealed a high correlation between different aspects of anti-fungal proteins. Five different pattern patterns have been detected in the anti-fungal chickpea proteins identified, including domain families associated with fungal resistance. The maximum likelihood of phylogenetic analysis was successful in distinguishing between anti-fungal chickpea proteins as seen in their protein patterns / domains.

Keywords: Chickpea, Fungal resistance, Phylogenetic analysis, Protein domain, Protein property.

\section{Introduction}

Chickpea (Cicer arietinum) is an important crop that delivers nutritious food to the increasing global community and it will become increasingly popular as a result of climate change. Production ranked third following beans with an average annual yield of over 11.5 million tons, where India has the highest share. Land allocated to chickpea has dramatically increased and is now reported at 14.56 million hectares. More than 2.3 million tons of chickpea reach world markets every year to fund the requirements of countries unable to satisfy domestic consumption (1). 
Chickpea yield is significantly affected by both abiotic as well as biotic stress susceptibility (2,3). Fungal infections have been shown to destructive effects on the chickpea production compared to various diseases triggered by a wide range of pathogens. Within numerous fungal diseases, the most prevalent foliar and root infections are the diseases caused by Ascochyta rabiei (Ascochyta blight) and Fusarium oxysporum (fusarium wilt), respectively, which cause serious crop yield decline (4).

The genome of chickpea $(2 \mathrm{n}=2 \mathrm{x}=16)$ is estimated to be $738.09 \mathrm{Mb}$ in length, where different cultivars whole genomes have been introduced for publicly use with more than $73 \%$ of the genomic content has been successfully sequenced. The chickpea gene pool is estimated to be about 29,000 genes, and about half $(49.41 \%)$ of the chickpea genome consists of transposable elements and unclassified repetitions. On the other hand, in species-specific groups, 4,468 chickpea genes occur, these groups may arise through structural rearrangements, as happens among the disease resistance genes of nucleotide-binding site leucine-rich repeat (NBS-LRR). In this regard, it has been stated that the chickpea genome has been observed as having 187 disease resistance gene homologs (RGHs) $(5,6)$.

The continuing breakthroughs in genome sequencing and genome-wide association studies have unlocked the ability to scan genomic content of chickpea for genes to control their resistance to multiple infections of the fungal disease. Several predicted genes have been reported to have been statistically associated with chickpea fungal resistance, including NBS-LRR receptor-like kinase, wall-associated kinase, zinc finger protein, and serine / threonine protein kinase (7). In addition, it has been reported that chickpea resistance to some fungal diseases, such as Ascochyta blight, may be linked to a number of motif families, such as AT-hook motif containing nuclear localized (AHL) (8). In addition, bioinformatics methods have been accelerated over the last few years and several genomic and molecular databases have been established (9). Such repositories could be used as a central stone in the quest for anti-fungal resistance in different plant species and in the analysis of their specific and special molecular structure $(10,11)$. Such bioinformatics tools have been used to study several gene families in chickpea, these families are considerably important in the plant defense system and essential membrane proteins $(12,13)$.

Genome-wide characterization of anti-fungal genes in chickpea may enable researchers and breeders to overcome different fungal infections and develop new cultivars with high tolerance and better yield. Our objective was to use comprehensive data analysis to locate and identify candidate genes for fungal disease resistance. We used a comprehensive bioinformatics pipeline of sequence alignment, phylogenetic analysis, protein chemical and physical properties assessment and domain structure classification. In order to study gene evolution and genetic diversity, we compared these genes with known anti-fungal genes in different species of plants.

\section{Materials and Methods}

Genomic sequences related to anti-fungal resistance have been downloaded from the NCBI database. (14). A total of 19721 sequences of proteins belonging to 187 species of plants were downloaded from NCBI. The chickpea genome sequence was downloaded from the http:/www.cicer.info database (5). Using the chickpea genome, the local BLAST+ (15) kit was used to create sequence database and align all anti-fungal amino acids with TBLASTN against the chickpea database. The NCBI TBLASTN online tool was used to annotate recovered sequences from the previous step. MEME suite (16) was used to explore patterns of amino acids in chickpea anti-fungal genes. The MegaX program was used to perform a phylogenetic analysis using a maximum likelihood algorithm(17). In order to assess the chemical and physical characteristics of the amino acids, the Pepstat program (18) was used through in-home perl scripts. These chemical properties are, A280 Molar Extinction Coefficients cystine bridges (A280-MECcb), A280 Molar Extinction Coefficients reduced (A280-MECr), Acidic (Ac), Aliphatic (Aph), Aromatic(Ar), Average Residue Weight (ARW), Basic (Bs), Charge (Chr), Charged (Chrd), Improbability of expression in inclusion bodies (IEEB), Isoelectric Point (IP), Molecular weight (MW), Non-polar (NP), Polar (Po), Residues (Re), Small (S), Tiny (T). The iTOL online tool was used to visualize phylogenetic trees combined with information on amino acids (19) $\square$. The statistical correlation analysis (pvalue $<0.01$ ) was conducted using $\mathrm{R}$ packages (20). The Circos package was used for displaying the genomic location of genes (21).

\section{Results and Discussion \\ Identification of chickpea anti-fungal genes}

Identifying anti-fungal genes in chickpea could provide a useful resource for plant breeding programs by narrowing the pool of targeted genes. We have successfully identified 23 potential anti-fungal genes on 10 different chromosomes and genomic scaffolds (File S1). The total number of amino acids was 7077, ranging from 147 to 866 , with an average of 307.7 amino acids. Chromosomes Ca2 and $\mathrm{Ca} 6$ have the highest number of genes (4 genes) followed by $\mathrm{Ca} 3$ and $\mathrm{Ca} 4$ (3 genes) (Figure 1 and Table 1). In this regard, the entire genome re-sequencing of chickpea was used to identify 12 chromosomal regions associated with resistance to Ascochyta Blight, all of which 
are located on $\mathrm{Ca} 4$ (7). In addition, 8 quantitative trait loci (QTLs) were identified on chromosomes Ca2, Ca3, Ca4, $\mathrm{Ca} 5$ and $\mathrm{Ca} 6$ for the resistance of the same disease (22).

\section{The chemical and physical properties of chickpea anti-fungal proteins}

The chemical properties of the chickpea anti-fungal proteins were assessed across 17 different chemical and physical features of the amino acids. The total amino acid MW was 765.4, ranging from 16.0 KDa (Ca AF17) to $97.7 \mathrm{KDa}$ (Ca AF9) with an average of $33.3 \mathrm{KDa}$ (Figure 2 and Table 2). By studying anti-fungal proteins in wheat total MW 1913 KDa with an average of $20 \mathrm{KDa}$ (10). The amino acids charge ranges from -25 to (Ca_AF13) to 14 (Ca_AF9) (Figure 2 and Table 2). The extinction coefficient is a measure of how much light at a given wavelength a chemical element attenuates. Calculating the content of the amino acid is necessary in order to determine the protein's molar extinction coefficient (23).

The A280 Molar Extinction Coefficients reduced (A280-MECr) and A280 molar extinction coefficients cystine bridges (A280-MECcb) are two separate extinction coefficient measures, where salt bridges are essential motifs of the tertiary protein structure and are mostly associated with the molecular influence force that maintains the protein's stability (24). The A280-MECr and A280-MECcb total values are 836030, 864530 $\mathrm{M}-1 \mathrm{~cm}-1$, ranging from 10430 and $11555 \mathrm{M}-1 \mathrm{~cm}-1(\mathrm{Ca}$ AF11) to 87560 and $90560 \mathrm{M}-1 \mathrm{~cm}-1$ (Ca AF9), respectively (Figure $\mathbf{2}$ and Table 2). In some anti-fungal wheat proteins, the A280-MECc and A280-MECr minimum scores were recorded as 1740 and 1490, with the highest scores being 104570 and 103820 respectively (10). Improbability of expression in inclusion bodies (IEEB) is a type of solubility measurement. In Escherichia coli, for example, recombinant protein can be produced either as insoluble in the bodies of inclusion or soluble throughout the cytosol (25). The total IEEB of chickpea anti-fungal protein was 18.33 ranging from 0 (Ca_AF11) to 0.972 (Ca_AF16) with a mean of 0.797 (Figure 2 and Table 2). The IEIB of anti-fungal amino acids revealed an average of 0.794 by examining wheat anti-fungal proteins, ranging from 0.504 to 0.977 (10). The average collective weight as per their length for all amino acid sequences is measure though The average residue weight (ARW).

Table 1: The chromosomal location and gene definition for identified anti-fungal genes in chickpea genome.

\begin{tabular}{|c|c|c|c|c|c|c|c|c|c|}
\hline$\overline{\text { Gene code }}$ & Chr. & start & end & gene name & Gene code & Chr. & start & end & gene name \\
\hline Ca_AF1 & Chr1 & 13449810 & 13450553 & cysteine-rich & Ca_AF13 & Chr5 & 15134097 & 15134777 & pathogenesis-related \\
\hline Ca_AF2 & Chr1 & 39499412 & 39500080 & thaumatin & Ca_AF14 & Chr5 & 64978467 & 64979294 & cysteine-rich \\
\hline Ca_AF3 & Chr2 & 15365865 & 15366560 & plasmodesmata-located & Ca_AF15 & Chr6 & 11037122 & 11037844 & pathogenesis-related \\
\hline Ca_AF5 & Chr2 & 22066674 & 22068239 & cysteine-rich & Ca_AF17 & Chr6 & 13070688 & 13071419 & cysteine-rich \\
\hline Ca_AF6 & Chr2 & 29604091 & 29604798 & thaumatin & Ca_AF18 & Chr6 & 65201755 & 65202474 & plasmodesmata-located \\
\hline Ca_AF7 & Chr3 & 39833663 & 39834379 & cysteine-rich & Ca_AF19 & Chr7 & 24258666 & 24259331 & thaumatin \\
\hline Ca_AF8 & Chr3 & 51987009 & 51987668 & cysteine-rich & Ca_AF20 & Chr8 & 18540320 & 18541342 & cysteine-rich \\
\hline Ca_AF9 & Chr3 & 59460263 & 59461033 & cysteine-rich & Ca_AF21 & Chr8 & 5747704 & 5748729 & thaumatin \\
\hline Ca_AF10 & Chr4 & 2480078 & 2480725 & cysteine-rich & Ca_AF22 & Scaffold0585 & 6485 & 7156 & thaumatin \\
\hline Ca_AF11 & Chr4 & 4601812 & 4602510 & cysteine-rich & Ca_AF23 & Scaffold4365 & 250412 & 251062 & pathogenesis-related \\
\hline Ca_AF12 & Chr4 & 56994913 & 56995608 & pathogenesis-related & & & & & \\
\hline
\end{tabular}




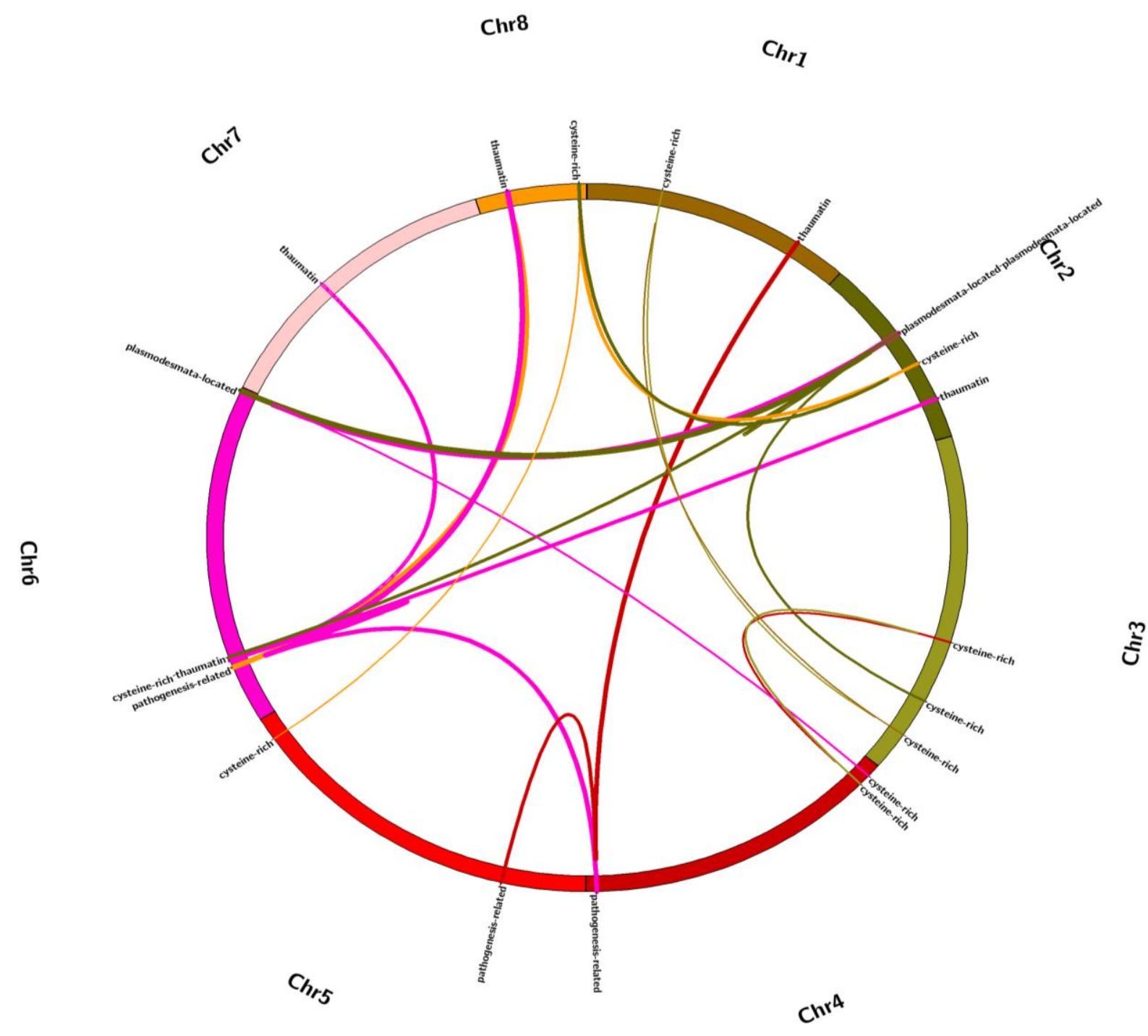

Figure 1 : The genomic location and suggested definition of predicated anti-fungal genes, where the width of the internal links indicates similarity percentage of gene sequences.

The total ARW was $2478.4 \mathrm{Da}$, where $\mathrm{Ca} \mathrm{AF} 13$ and Ca AF14 have the minimum and maximum values of 101.8 $\mathrm{Da}$ and 116.7 $\mathrm{Da}$, with an average of $107.7 \mathrm{Da}$, respectively. The IEIB of anti-fungal amino acids revealed an average of 0.794 , ranging from 0.504 to 0.977 , through examining wheat anti-fungal proteins (10). The isoelectric point (IP) is the $\mathrm{pH}$ level with which the net charge of the protein is positive, and is correlated with amino acid composition and protein structure (26). The IP of chickpea anti-fungal proteins range from 3.9 (Ca_AF13) to 8.9 (Ca_AF19) with a mean of 6 (Figure 2 and Table 2). Thus, it revealed a collective IP in wheat anti-fungal proteins with an average of 6,402 , ranging from 4 to 10.4 in wheat (10).

In addition, the folded structure of a protein becomes less desirable in terms of thermodynamics because it decreases the protein disorder or entropy, where non-polar chains tend to squeeze inside the protein while polar chains push outside the molecule (27). The non-polar (NP) values ranges from 49.2 (Ca_AF20) to 62.1 (Ca_AF16) with an average of 56 (Figure 2 and Table 2). The non-polar and polar amino acid scores ranged from 48.81 and 30.081 to 69.919 and 51.19 respectively, in wheat anti-fungal proteins (10). Basic amino acids have a certain basic group within the chain whereas acidic amino acids have an acidic group within the chain. basic amino acids have high pKa while acidic amino acids have low pKa. The count of basic and acidic amino acids range from 9.011 and 9.359 to (Ca_AF13 and Ca_AF16) to 13.613 and 16.915 (Ca_AF19 and Ca_AF11) (Figure 2 and Table 2). 

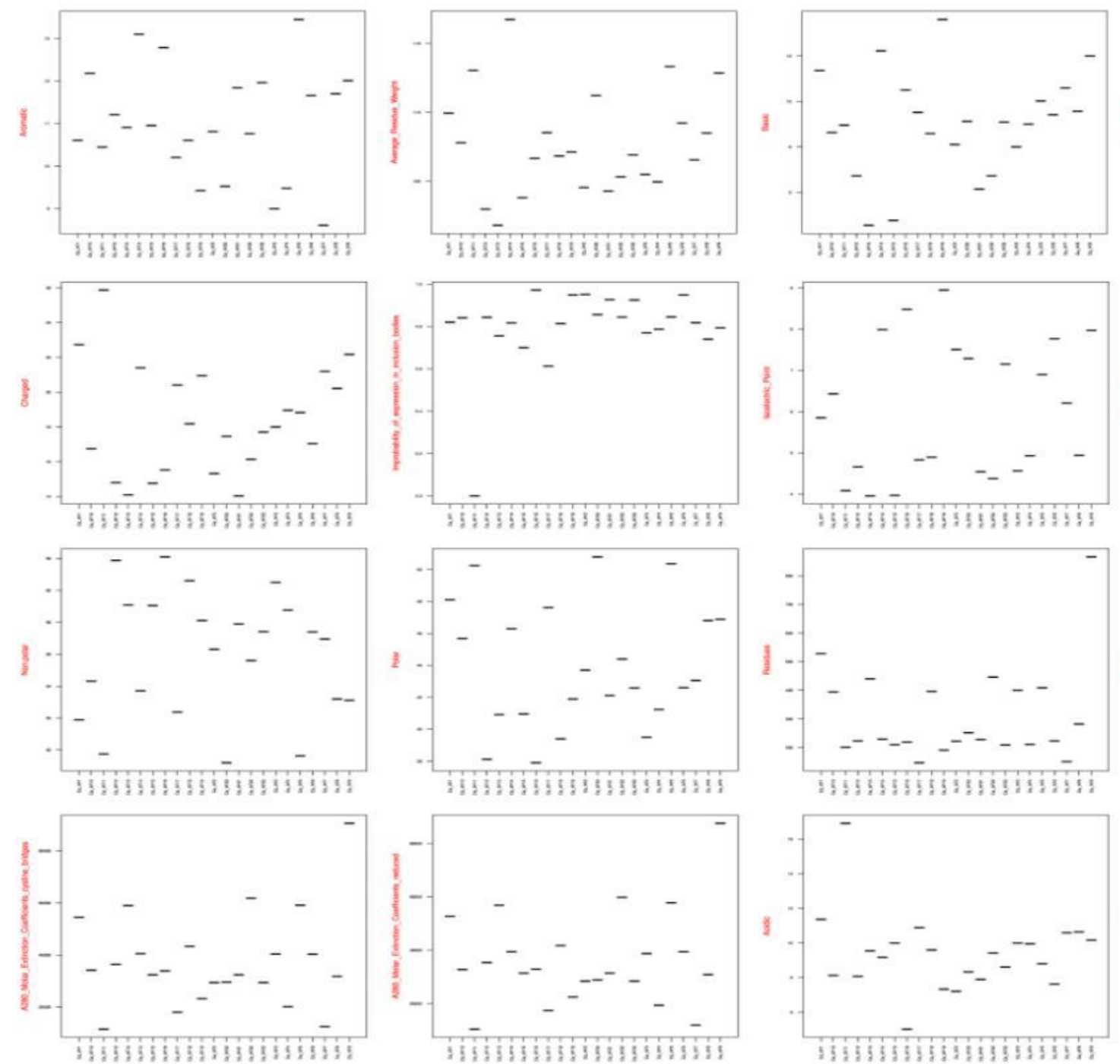

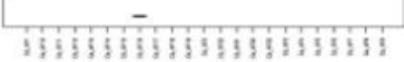
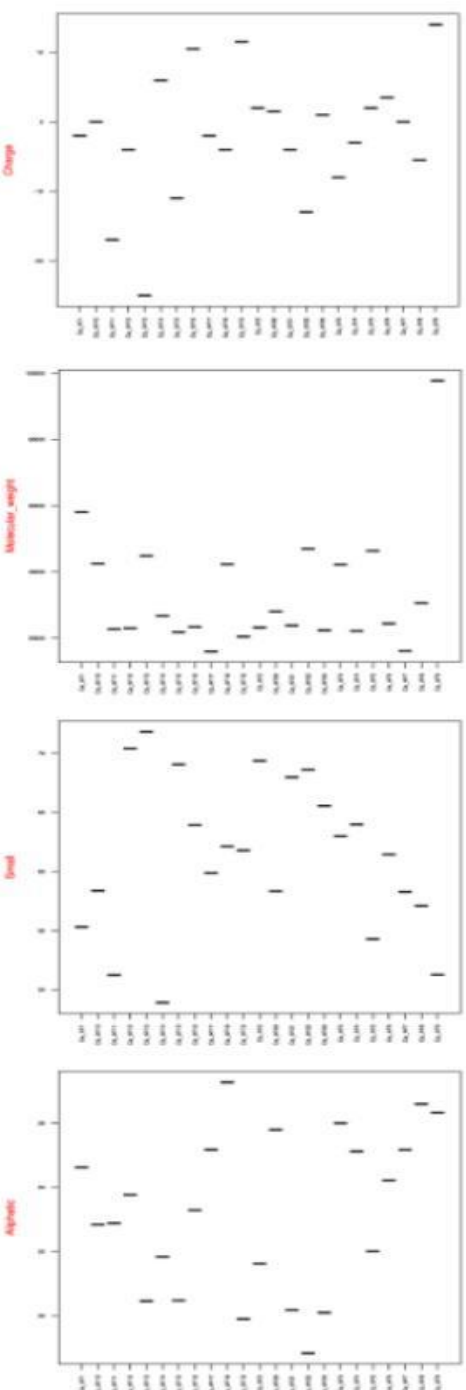

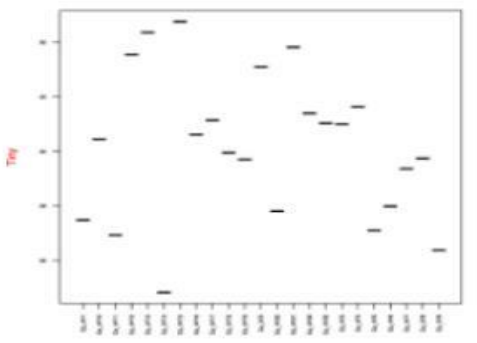

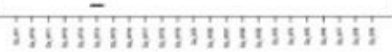

Figure 2: The chemical and physical properties of identified anti-fungal proteins in chickpea. 
Table 2: Chemical properties of identified anti-fungal proteins in chickpea.

\begin{tabular}{|c|c|c|c|c|c|c|c|c|c|c|c|c|c|c|c|c|c|}
\hline protein & A280-MECcb & A280-MECr & Ac & Aph & Ar & ARW & Bs & Chr & Chrd & IEEB & IP & MW & NP & Po & $\operatorname{Re}$ & $\mathbf{s}$ & $\mathbf{T}$ \\
\hline Ca_AF1 & 54470 & 52720 & 11.364 & 24.621 & 10.606 & 109.947 & 11.364 & -2 & 22.727 & 0.82 & 5.8518 & 58051.77 & 51.894 & 48.106 & 528 & 55.303 & 33.712 \\
\hline Ca_AF2 & 29420 & 28420 & 7.207 & 21.622 & 10.811 & 104.536 & 8.108 & 2 & 15.315 & 0.951 & 7.5063 & 23206.95 & 56.306 & 43.694 & 222 & 69.369 & 47.748 \\
\hline Ca_AF3 & 40365 & 38740 & 10 & 26 & 9 & 105.494 & 8 & -8 & 18 & 0.77 & 4.5636 & 42197.5 & 60.5 & 39.5 & 400 & 63 & 42.5 \\
\hline Ca_AF4 & 20120 & 19370 & 9.953 & 25.118 & 9.479 & 104.952 & 9.005 & -3 & 18.957 & 0.787 & 4.929 & 22144.77 & 58.768 & 41.232 & 211 & 63.981 & 44.076 \\
\hline Ca_AF5 & 59135 & 57760 & 8.802 & 22.005 & 13.447 & 113.33 & 10.024 & 2 & 18.826 & 0.845 & 6.899 & 46352.15 & 49.633 & 50.367 & 409 & 54.279 & 32.763 \\
\hline Ca_AF6 & 40295 & 39420 & 7.623 & 24.215 & 11.659 & 109.223 & 9.417 & 3.5 & 17.04 & 0.949 & 7.7696 & 24356.69 & 57.399 & 42.601 & 223 & 61.435 & 34.978 \\
\hline Ca_AF7 & 12545 & 11920 & 10.596 & 25.166 & 8.609 & 106.551 & 10.596 & 0 & 21.192 & 0.818 & 6.208 & 16089.2 & 56.954 & 43.046 & 151 & 58.278 & 38.411 \\
\hline Ca_AF8 & 31830 & 30830 & 10.638 & 26.596 & 11.702 & 108.504 & 9.574 & -5.5 & 20.213 & 0.74 & 4.941 & 30598.04 & 53.191 & 46.809 & 282 & 57.092 & 39.362 \\
\hline Ca_AF9 & 90560 & 87560 & 10.162 & 26.328 & 12.009 & 112.861 & 12.009 & 14 & 22.171 & 0.793 & 7.9722 & 97737.52 & 53.118 & 46.882 & 866 & 51.27 & 30.947 \\
\hline Ca_AF10 & 34155 & 32780 & 8.122 & 22.843 & 12.183 & 107.791 & 8.629 & 0 & 16.751 & 0.841 & 6.4334 & 42469.67 & 54.315 & 45.685 & 394 & 58.376 & 41.117 \\
\hline Ca_AF11 & 11555 & 10430 & 16.915 & 22.886 & 10.448 & 113.048 & 8.955 & -17 & 25.871 & 0 & 4.082 & 22722.56 & 49.751 & 50.249 & 201 & 51.244 & 32.338 \\
\hline Ca_AF12 & 36410 & 35410 & 8.072 & 23.767 & 11.211 & 102.971 & 6.726 & -4 & 14.798 & 0.843 & 4.6572 & 22962.57 & 61.883 & 38.117 & 223 & 70.404 & 48.879 \\
\hline Ca_AF13 & 58965 & 56840 & 9.545 & 20.455 & 10.909 & 101.798 & 4.545 & -25 & 14.091 & 0.756 & 3.9557 & 44790.92 & 59.091 & 40.909 & 440 & 71.818 & 50.909 \\
\hline Ca_AF14 & 40545 & 39420 & 9.17 & 21.834 & 13.1 & 116.75 & 12.227 & 6 & 21.397 & 0.817 & 7.9878 & 26735.85 & 53.712 & 46.288 & 229 & 48.908 & 27.074 \\
\hline Ca_AF15 & 32400 & 31400 & 10 & 20.476 & 10.952 & 103.8 & 4.762 & -11 & 14.762 & 0.7 & 3.9687 & 21797.95 & 59.048 & 40.952 & 210 & 69.048 & 51.905 \\
\hline Ca_AF16 & 33890 & 32890 & 5.023 & 23.288 & 12.785 & 106.665 & 10.502 & 10.5 & 15.525 & 0.972 & 8.4799 & 23359.67 & 62.1 & 37.9 & 219 & 63.927 & 41.553 \\
\hline Ca_AF17 & 18045 & 17420 & 10.884 & 25.17 & 10.204 & 108.53 & 9.524 & -2 & 20.408 & 0.613 & 4.8281 & 15953.84 & 52.381 & 47.619 & 147 & 59.864 & 42.857 \\
\hline Ca_AF18 & 43345 & 41720 & 9.596 & 27.273 & 10.606 & 106.838 & 8.586 & -4 & 18.182 & 0.814 & 4.8941 & 42307.82 & 60.606 & 39.394 & 396 & 62.121 & 39.899 \\
\hline Ca_AF19 & 23210 & 22460 & 7.33 & 19.895 & 9.424 & 107.128 & 13.613 & 11.5 & 20.942 & 0.949 & 8.9491 & 20461.39 & 58.115 & 41.885 & 191 & 61.78 & 39.267 \\
\hline Ca_AF20 & 29630 & 28880 & 8.333 & 25.794 & 9.524 & 111.225 & 9.127 & 1.5 & 17.46 & 0.856 & 7.2867 & 28028.72 & 49.206 & 50.794 & 252 & 58.333 & 34.524 \\
\hline Ca_AF21 & 32400 & 31400 & 7.895 & 20.175 & 11.842 & 104.278 & 6.14 & -4 & 14.035 & 0.927 & 4.542 & 23775.41 & 57.895 & 42.105 & 228 & 67.982 & 49.561 \\
\hline Ca_AF22 & 61820 & 59820 & 9.417 & 18.834 & 10.762 & 105.318 & 6.726 & -13 & 16.143 & 0.844 & 4.3753 & 46971.95 & 55.605 & 44.395 & 446 & 68.61 & 43.498 \\
\hline Ca_AF23 & 29420 & 28420 & 8.612 & 20.096 & 11.962 & 106.915 & 9.091 & 1 & 17.703 & 0.925 & 7.1537 & 22345.18 & 57.416 & 42.584 & 209 & 65.55 & 42.584 \\
\hline
\end{tabular}


On the other hand, in addition to the chickpea genes retrieved through this study, we have studied the chemical and physical properties of 1216 anti-fungal proteins identified in different plant species (Figure 3 and Table S2). The protein MW range from $21 \mathrm{KDa}$ (Silene latifolia) to $97.7 \mathrm{KDa}$ (Cicer arietinum) while the protein charge range from -25 (Cicer arietinum) to 21 (Rosa chinensis) (Figure 3 and Table S2).
The minimum ARW was $99.74 \mathrm{KDa}$ (Striga asiatica) and the maximum $116.75 \mathrm{KDa}$ (Cicer arietinum) (Figure 3 and Table S2). The A280-MECr and A280-MECcb range from 30193 and 31133 to 87560 and $90560 \mathrm{M}-1 \mathrm{~cm}-1$, respectively (Figure 3 and Table S2). The charged amino acids range from 8.108 (Cephalotus follicularis) to 26.941 (Populus trichocarpa) (Figure 3 and Table S2).

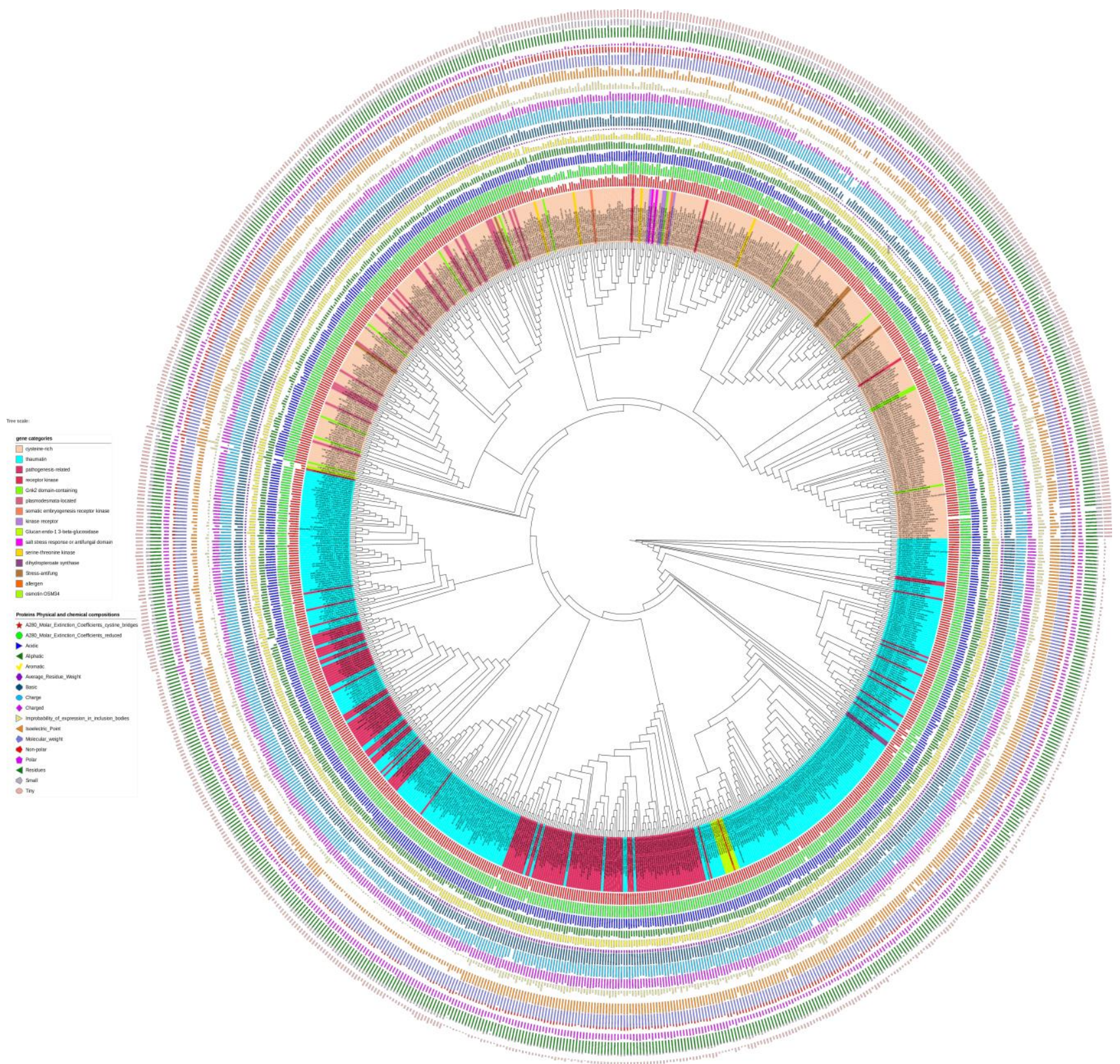

Figure 3 : The phylogenetic tree developed using multiple sequence alignment of chickpea anti-fungal proteins and other species, where its chemical and physical properties are plotted. 

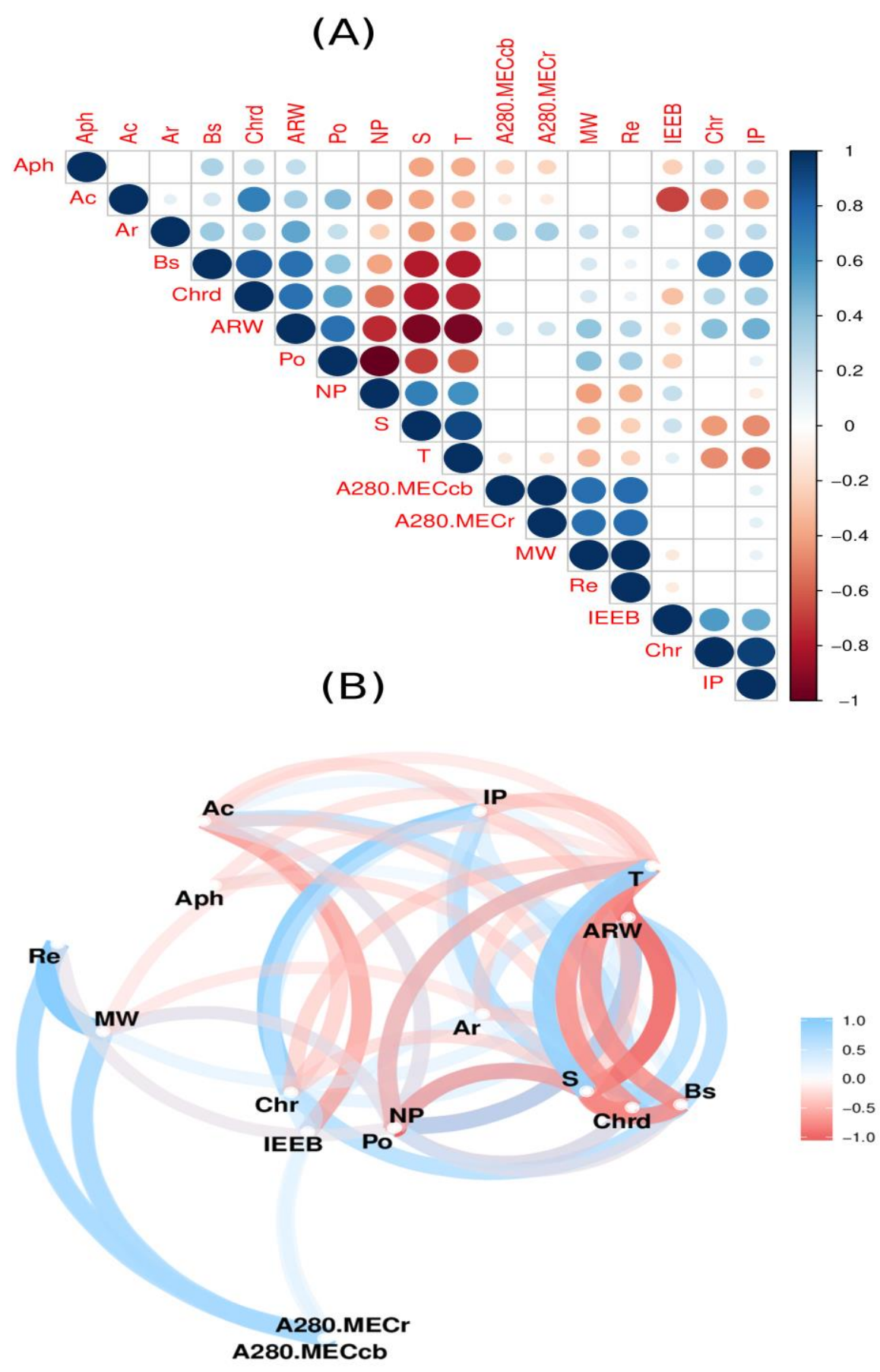

Figure 4 :Statistical correlation between different chemical and physical properties of anti-fungal proteins; (A) the heatmap of inter-correlation matrix and $(\mathbf{B})$ the correlation networks, where pvalue $>0.01$ and $\mathrm{R}^{2}>0.3$.

\section{Phylogenetic analysis and domain identification of anti-fungal proteins}

The phylogenetic tree constructed using 1216 anti-fungal proteins of 187 was clustered into 11 clusters (Figure 3). The anti-fungal chickpea proteins identified are cysteine-rich (10), thaumatin (6), pathogenesis-related (4) and plasmodesmata (3) proteins (Figure 3).
A protein sequence motif is a brief pattern that is preserved by nature. For proteins, a motif may relate to the active site of an enzyme or to a functional unit required to properly fold proteins. Hence, sequence motifs are among the basic functional components of molecular evolution (16). Five specific motifs for amino acids were discovered among the sequences of identified anti-fungal proteins of chickpea 
(Figure 5). The maximum likelihood phylogenetic analysis was successful in distinguishing between anti-fungal chickpea proteins as illustrated by their protein motifs / domains. These motifs are motif1 (ELME000385), motif2 (ELME000094), motif3 (ELME000321), motif4 (ELME000003), and motif5 (ELME000287) (Figure 5). Motif1 is very similar to ELME000385 (pvalue of 1.60e-03), which functions as Mtr4-Air2-interaction site. This domain distinguishes the TRAMP complex, which engages in the nucleus with exosome-mediated degradation of abnormal RNAse. Oligo-adenylated tails are introduced to substrates of abnormal RNA by Air2 and Mtr4 , thus highlighting them for degradation (28). Motif2 has a high significance similarity with Integrin binding sites (ELME000094) with a pvalue of 1.16e-05. Integrins are cell surface receptors which are responsible for cell migration, cell adhesion to extracellular matrix, and cell adhesion to cells (29) $\square$. Motif3 is similar to caspase cleavage motif (ELME000321) with a pvalue of 5.46e-03. Proteases caspases-3 and-7 play a major role in programmed cell apoptosis, and non-apoptotic caspases include involvement in immune response (30). Similarly, pattern 5 is similar to IAP-binding pattern (IBM): (ELME000287) that distinguishes Apoptosis Protein Inhibitor (IAP) which exhibits several immune functions, mitosis regulation, TNF-receptor signal transduction, and many more (31) $\square$. Finally, motif4 was in high similar to WW domain ligands (ELME000003) motif, which are small but widespread domains are found in various regulatory circumstances (16).

The maximum likelihood of phylogenetic analysis was successful in distinguishing between anti-fungal chickpea proteins as seen in their protein patterns/domains. Where it cluster chickpea genes into 4 clusters (Figure 6).
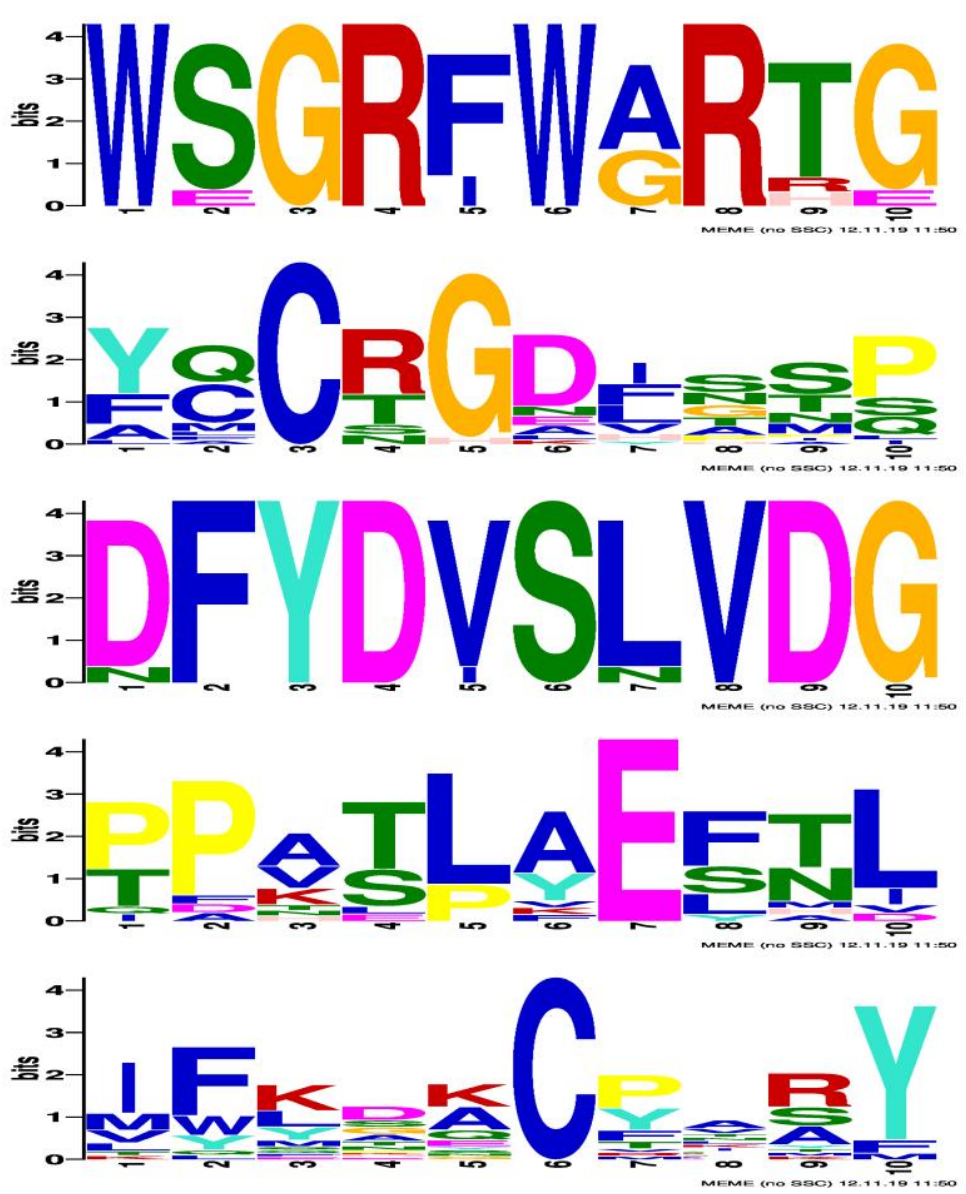

Figure 5: The domains/motifs found by the MeMe tool in chickpea predicated anti-fungal proteins. 


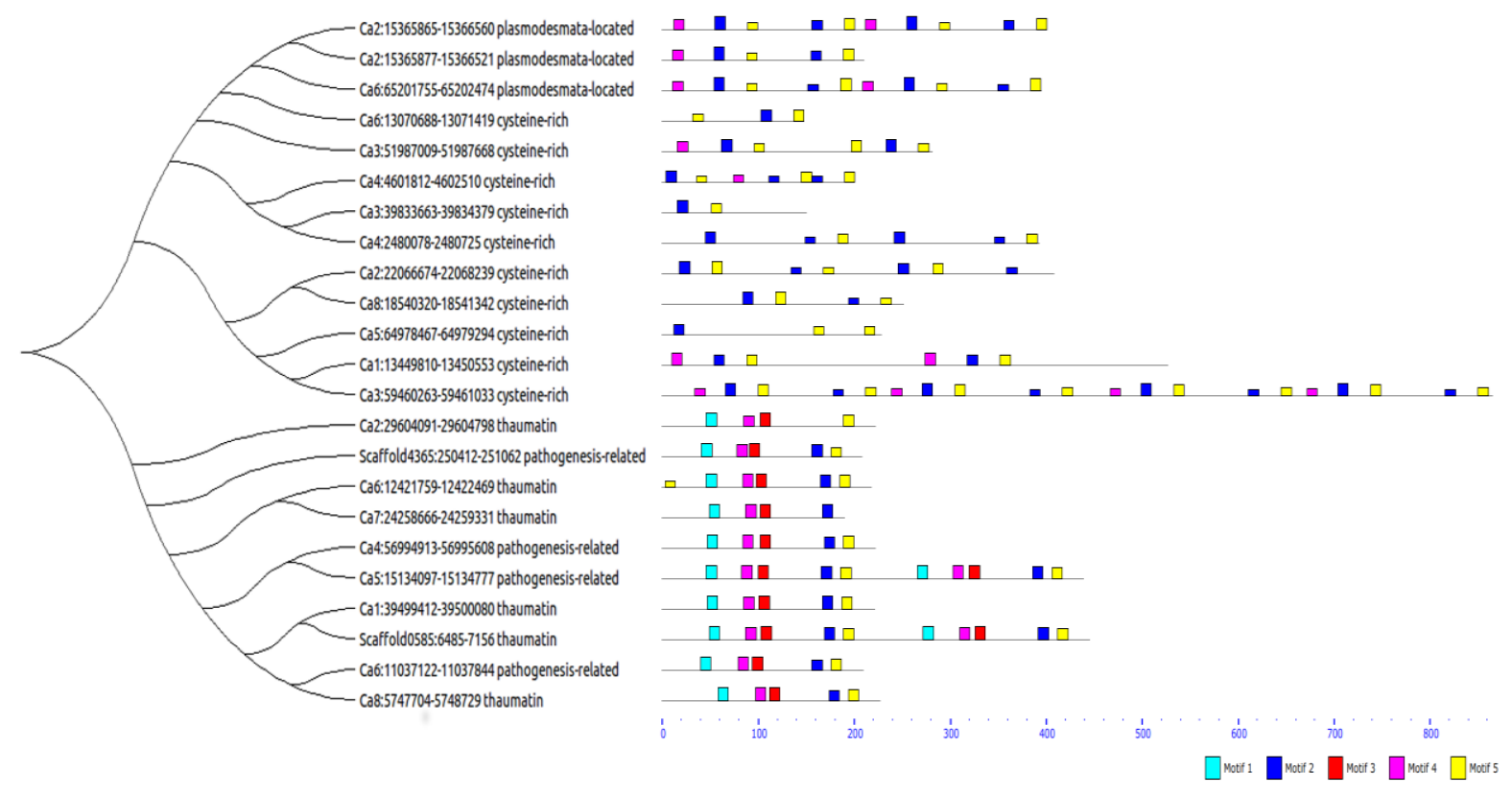

Figure 6: The phylogenetic analysis of chickpea anti-fungal proteins, where the protein motif structures are shown as detected using MeMe tool.

\section{Conclusion}

It was very helpful to predict anti-fungal resistance genes using publicly available repositories and indicated that several chickpea genes could be used to limit genetic research of genes that hold the key to fungal resistance in chickpea. We have successfully identified 23 potential anti-fungal genes on 10 different chromosomes and genomic scaffolds. A high number of anti-fungal chickpea proteins are cysteine-rich (20), thaumatin (9), and pathogenesis-related (8), which could indicate the importance of these gene classes in chickpea resistance to fungal. In addition, the chemical and physical analysis shed light on the uniqueness and consistency of these proteins, where several of these parameters could be used in future research to identify anti-fungal genes in different plant species. Moreover, the domain identification analysis identified several potential anti-fungal protein domains such as TRAMP complex and caspase cleavage motifs.

\section{Supplementary Files}

The Supplementary Material for this article can be found online at: https://doi.org/10.36462/H.BioSci.20194

Supplementary file 1: The amino acid sequences of anti-fungal genes identified in chickpea.

Supplementary file 2: The physical and chemical properties of some anti-fungal proteins in plant species.

\section{References}

1. Merga B, Haji J. Economic importance of chickpea: Production, value, and world trade. Cogent Food Agric. 2019;5(1):1615718.

2. Ahmed SM, Alsamman AM, Mubarak MH, Badawy MA, Kord MA, Momtaz OA, et al. Dowsing for salinity tolerance related genes in chickpea through genome wide association and in silico PCR analysis. bioRxiv. 2019;519744.

3. Hamwieh A, Imtiaz M, Malhotra RS. Multi-environment QTL analyses for drought-related traits in a recombinant inbred population of chickpea (Cicer arientinum L.). Theor Appl Genet. 2013;126(4):1025-38.

4. Kukreja S, Salaria N, Thakur K, Goutam U. Fungal Disease Management in Chickpea: Current Status and Future Prospects. In: Fungi and their Role in Sustainable Development: Current Perspectives. Springer; 2018. p. 293-309.

5. Edwards D. Improved kabuli reference genome. CyVerse Data Commons Dataset. 2016;10:P2G596.

6. Varshney RK, Song C, Saxena RK, Azam S, Yu S, Sharpe AG, et al. Draft genome sequence of chickpea (Cicer arietinum) provides a resource for trait improvement. Nat Biotechnol. 2013;31(3):240.

7. Li Y, Ruperao P, Batley J, Edwards D, Davidson J, Hobson K, et al. Genome analysis identified novel 
candidate genes for ascochyta blight resistance in chickpea using whole genome re-sequencing data. Front Plant Sci. 2017;8:359.

8. Kumar K, Purayannur S, Kaladhar VC, Parida SK, Verma PK. mQTL-seq and classical mapping implicates the role of an AT-HOOK MOTIF CONTAINING NUCLEAR LOCALIZED (AHL) family gene in A scochyta blight resistance of chickpea. Plant Cell Environ. 2018;41(9):2128-40.

9. Awan Z. Plant Molecular Biology Databases. Highlights Biosci. 2019;1-7.

10. Nassar AE, Mousa KH, Madbouly AA, Ibrahim SD, Alsamman AM. Identification of Genes for Wheat Fungal Resistance Using Bioinformatics Techniques. Highlights Biosci. 2018;1(November):1-10.

11. Alsamman AM, Ibrahim SD, Hamwieh A. KASPspoon: an in vitro and in silico PCR analysis tool for high-throughput SNP genotyping. Bioinformatics. 2019;

12. Palomino C, Satovic Z, Cubero JI, Torres AM Identification and characterization of NBS--LRR class resistance gene analogs in faba bean (Vicia faba L.) and chickpea (Cicer arietinum L.). Genome. 2006;49(10):1227-37.

13. Deokar AA, Tar'an B. Genome-wide analysis of the aquaporin gene family in chickpea (Cicer arietinum L.). Front Plant Sci. 2016;7:1802.

14. Maglott D, Ostell J, Pruitt KD, Tatusova T. Entrez Gene: gene-centered information at NCBI. Nucleic Acids Res. 2010;39(suppl_1):D52--D57.

15. Altschul SF, Madden TL, Schäffer AA, Zhang J, Zhang Z, Miller W, et al. Gapped BLAST and PSI-BLAST: a new generation of protein database search programs. Nucleic Acids Res. 1997;25(17):3389-402.

16. Bailey TL, Boden M, Buske FA, Frith M, Grant CE, Clementi L, et al. MEME SUITE: tools for motif discovery and searching. Nucleic Acids Res. 2009;37(suppl_2):W202--W208.

17. Kumar S, Stecher G, Li M, Knyaz C, Tamura K. MEGA $\mathrm{X}$ : molecular evolutionary genetics analysis across computing platforms. Mol Biol Evol. 2018;35(6):1547-9.

18. Rice P, Longden I, Bleasby A. EMBOSS: the European molecular biology open software suite. Elsevier current trends; 2000.

19. Letunic I, Bork P. Interactive Tree Of Life (iTOL): an online tool for phylogenetic tree display and annotation. Bioinformatics. 2006;23(1):127-8.
20. Gentleman R. R programming for bioinformatics. Chapman and Hall/CRC; 2008.

21. Krzywinski M, Schein J, Birol \.Inanç, Connors J, Gascoyne R, Horsman D, et al. Circos: an information aesthetic for comparative genomics. Genome Res. 2009;19(9):1639-45.

22. Deokar A, Sagi M, Tar'an B. Genome-wide SNP discovery for development of high-density genetic map and QTL mapping of ascochyta blight resistance in chickpea (Cicer arietinum L.). Theor Appl Genet. 2019;132(6):1861-72.

23. Gill SC, Von Hippel PH. Calculation of protein extinction coefficients from amino acid sequence data. Anal Biochem. 1989;182(2):319-26.

24. Pylaeva S, Brehm M, Sebastiani D. Salt Bridge in Aqueous Solution: Strong Structural Motifs but Weak Enthalpic Effect. Sci Rep. 2018;8.

25. Davis GD, Elisee C, Newham DM, Harrison RG. New fusion protein systems designed to give soluble expression in Escherichia coli. Biotechnol Bioeng. 1999;65(4):382-8.

26. Righetti PG. Determination of the isoelectric point of proteins by capillary isoelectric focusing. J Chromatogr A. 2004;1037(1-2):491-9.

27. Broome BM, Hecht MH. Nature disfavors sequences of alternating polar and non-polar amino acids: implications for amyloidogenesis. $\mathrm{J}$ Mol Biol. 2000;296(4):961-8.

28. LaCava J, Houseley J, Saveanu C, Petfalski E, Thompson E, Jacquier A, et al. RNA degradation by the exosome is promoted by a nuclear polyadenylation complex. Cell. 2005;121(5):713-24.

29. Curnis F, Longhi R, Crippa L, Cattaneo A, Dondossola E, Bachi A, et al. Spontaneous formation of L-isoaspartate and gain of function in fibronectin. J Biol Chem. 2006;281(47):36466-76.

30. Zhang Y, Center DM, David MH, Cruikshank WW, Yuan J, Andrews DW, et al. Processing and activation of pro-interleukin-16 by caspase-3. J Biol Chem. 1998;273(2):1144-9.

31. Crook NE, Clem RJ, Miller LK. An apoptosis-inhibiting baculovirus gene with a zinc finger-like motif. J Virol. 1993;67(4):2168-74. 